УДК 378.027 .7

DOI:

Оксана Кіліченко, кандидат педагогічних наук, доиент кафедри педагогіки початкової освіти

ДВНЗ “Прикарпатський національний університет імені Василя Стефаника"

\title{
ПІДГОТОВКА СТУДЕНТІВ ДО ПЕДАГОГІЧНОӤ ВЗАЄМОДІЇ ІЗ ДІТЬМИ ДОШКІЛЬНОГО І МОЛОДШОГО ШКІЛЬНОГО ВІКУ ЗІ ВНУТРІШНЬО ПЕРЕМШЩЕНИХ СІМЕЙ
}

У статті розглянуто особливості підготовки майбутніх педагогів до педагогічної взаємодії з дітьми дошкільного і молодшого шкільного віку зі внутрішньо переміщчених сімей.

Зазначено, щуо такі діти потрапляють в нові умови освітнього та національного середовища, внаслідок чого виникають проблеми з адаптацуією до соцчікультурного середовища. Вирішальну роль у процесі адаптаціï дитини відіграє педагог.

Визначено, щзо важливим напрямом підготовки до педагогічної взаємодії є впровадження в освітній прочес практики розв 'язування навчально-професійних ситуацій з використанням технологї̈ саsе-stиdy.

Ключові слова: внутрішньо перемішені сім' $і$; педагогічна взаємодія; підготовка до педагогічної взасмодіі; навчально-професійні ситуації.

Jim. 11.

Oksana Kilichenko, Ph.D.(Pedagogy), Associate Professor of the Primary Education Pedagogy Department State Higher Educational Institution Vasyl Stefanyk Precarpathian National University

\section{PREPARING STUDENTS FOR PEDAGOGICALINTERACTION WITH CHILDREN OF PRESCHOOLAND PRIMARY SCHOOLAGE FROM INTERNALLY DISPLACED FAMILIES}

The article studies the peculiarities of preparation of future teachers for pedagogical interaction with children of preschool and primary school age from internally displaced families. It is noted that such children fall into new conditions of educational and national environment and their system of value-cognitive orientations is reorganized, new types of interpersonal relations are formed, and new ways of cognitive activity, social activity are mastered. As a result, there are problems with adaptation to the socio-cultural environment. A crucial role in the process of adaptation of the child is played by the teacher, who not only deeply mastered the pedagogical theory, methods of teaching and education, but also gained practical experience in the technique of pedagogical interaction with pupils.

It is determined that an important direction of the preparation for pedagogical interaction is the introduction of solving educational and professional situations in the educational process. The article analyzes the concepts of "educational and professional situations", "pedagogical situations", "pedagogical tasks", and "tasks". It was found that in the preparation of future teachers for pedagogical interaction with children of preschool and primary school age from internally displaced families an important role belongs to the process of solving educational and professional situations using case-study technology, which includes two stages: creating clusters of pedagogical situations and solving them by discussing and playing situations through simulation of role-playing and business games.

During the COVID 19 pandemic, when distance learning forms were used, Padlet and EDpuzzle multimedia resources were presented to form cases. It is worth to note that the introduction of the process of solving educational and professional situations in the preparation of future teachers for pedagogical interaction with children of preschool and primary school age from internally displaced families is effective in using a coaching approach to the organization of the educational environment in higher education establishments.

Keywords: internally displaced families; pedagogical interaction; preparation for pedagogical interaction; educational and professional situations.

П остановка проблеми. Характерною ознакою сучасного українського суспільства $є$ наявність "внутрішньо переміщених осіб”. Сьогоднішній внутрішній міграції невластиве організоване переселення та набір робочої сили і найчастіше вона має вимушений характер і викликана воєнним конфліктом з 2014 р. Ї̈̈ причинами є світоглядні суперечності; невизначеність правового статусу, неможливість ведення підприємницької діяльності через неврегульованість правового поля та економічних санкцій, страхи, що викликані історичною пам'яттю, тощо [11].

У Законі України "Про забезпечення прав і свобод внутрішньо переміщених осіб" у статті 1 вказується, що “Внутрішньо переміщеною особою 


\section{ПІДГОТОВКА СТУДЕНТІВ ДОПЕДАГОГІЧНОЇ ВЗАЄМОДІЇ ІЗ ДІТЬМИ ДОШКІЛЬНОГОІМОЛОДШОГО ШКІЛЬНОГО ВІКУ ЗІ ВНУТРІШНЬО ПЕРЕМІЩЕНИХ СІМЕЙ}

$\epsilon$ громадянин України, іноземець або особа без громадянства, яка перебуває на території України на законних підставах та має право на постійне проживання в Україні, яку змусили залишити або покинути своє місце проживання у результаті або 3 метою уникнення негативних наслідків збройного конфлікту, тимчасової окупації, повсюдних проявів насильства, порушень прав людини та надзвичайних ситуацій природного чи техногенного характеру" [4].

У Міністерстві соціальної політики зазначено, що “Станом на 6 квітня 2021 р., за даними Сдиної інформаційної бази даних про внутрішньо переміщених осіб, взято на облік 1464171 переселенця 3 тимчасово окупованих територій Донецької та Луганської областей та АР Крим" [5].

Серед означеної категорії населення багато дітей, які потрапляють в нові умови освітнього та національного середовища.

Погоджуємося із думкою Т. Атрощенко і Л. Зданевич, що українська освіта i, зокрема дошкільна та початкова, не може повністю розв'язати політичні, економічні, етнічні проблеми. “Але вона може зробити істотний внесок у раннє формування багатоукладного менталітету, виховання підростаючого покоління поваги до культур різних народів" $[1,7]$.

Складність процесу адаптації дітей полягає ще й у тому, що у них здійснюється перебудова системи ціннісно-пізнавальних орієнтацій особистості, формуються нові типи міжособистісних стосунків, засвоюються нові способи пізнавальної діяльності, соціальної активності [8].

Безперечно, вирішальну роль у процесі адаптації дитини відіграє педагог, який не тільки глибоко оволодів педагогічною теорією, методикою навчання і виховання, але й здобув практичні знання техніки педагогічної взаємодії iз вихованцями.

Ось чому важливим є уміння педагога організовувати позитивну педагогічну взаємодію із дітьми дошкільного і молодшого шкільного віку зі категорії внутрішньо переміщених осіб, а звідси і виникає проблема підготовки студентів до неї на педагогічному факультеті.

Аналіз останніх досліджень і публікацій. Аналіз філософо-педагогічних джерел засвідчує, що тлумачення категорії “суб'єкт-об'єкт” знаходимо ще у філософії Канта. Необхідність взаємної активності вихователя і вихованців у педагогічному процесі наголошували Я. Коменського, Ж.-Ж.Руссо, К. Ушинського, М. Пирогова, які звертали увагу на важливість спеціальної підготовки до неї.
Обгрунтування значення терміна знаходимо у Ю. Бабанського, І. Беха, Б. Гершунського, В. КанКалика, О. Киричука, Л. Коваль, Л. Кондрашової, Ю. Косенко, О. Матвієнко, К. Петрик, О.Савченко, Р. Скульського та ін.

Пропонована стаття має на меті визначити особливості підготовки майбутніх педагогів до педагогічної взаємодії із дітьми дошкільного і молодшого шкільного віку зі категорії внутрішньо переміщених осіб під час пандемії Covid-19.

Виклад основного матеріалу дослідження. Аналізуючи поняття "педагогічна взаємодія", О. Киричук зазначав, що “взаємодія у широкому розумінні слова - філософська категорія, що охоплює процеси впливу об'єктів (суб'єктів) один на одного, їхню взаємну обумовленість і взаємозміну; взаємний зв'язок соціальних явищ, як на рівні суспільства в цілому, так і на рівні функціонування його окремих груп, індивідів; вона охоплює всі види соціальних процесів і людської діяльності (праця, пізнання спілкування, виховання і т.д.)" $[6,3]$.

Педагогічні взаємодії як видовому поняттю притаманні властивості взаємодії взагалі, і певні особливості. Ї̈̈ проявами є спілкування, стосунки (взаємостосунки), дії (діяльність), що побудовані на співактивності педагога і вихованців і які обмежені рамками освітнього процесу. Вона, як і будь-яка взаємодія, складається зі структурних одиниць, певних комунікативних актів.

Тому одним із основних напрямів підготовки майбутніх педагогів до педагогічної взаємодії із дітьми дошкільного і молодшого шкільного віку зі категорії внутрішньо переміщених осіб, на нашу думку, є впровадження в освітній процес ЗВО практики розв'язування навчально-професійних ситуацій.

У сучасних науково-педагогічних дослідженнях знаходимо різне розуміння поняття “навчальнопрофесійних ситуацій”. Проведений теоретичний аналіз засвідчує, що їх розглядають, як:

- фрагмент професійної діяльності;

- систему суб'єктивних і об'єктивних елементів, що об'єднуються у діяльності суб'єкта;

- сукупність елементів середовища, або як фрагмент середовища на певному етапі життєдіяльності індивіда, тобто це умови і обставин, за яких фахівці виконують з різним ступенем успішності професійні функції.

На нашу думку, навчально-професійні ситуації відображають фрагмент освітнього процесу, в якому відображено взаємодію вихователя і вихованців та який є основою для дослідження, аналізу, розв'язання, проєктування з метою професійного зростання педагогів $[7,50]$. 


\section{ПІДГОТОВКА СТУДЕНТІВ ДОПЕДАГОГІЧНОӤ ВЗАЄМОДІЇ ІЗ ДІТЬМИ ДОШКІЛЬНОГО ІМОЛОДШОГО ШКІЛЬНОГО ВІКУ ЗІ ВНУТРІШНЬО ПЕРЕМІЩЕНИХ СІМЕЙ}

Для визначення змісту навчально-професійних ситуацій розглядаємо такі проблеми: хто є об'єктом, а хто є суб'єктом ситуацій, з якою метою і для чого варто аналізувати, розв'язувати, прогнозувати ситуації, які конкретні умови впливають на хід протікання ситуацій, в яких освітніх умовах вони аналізуються (склад студентів, курс, дисципліна тощо).

У сучасній науково-педагогічній літературі натрапляємо також такі поняття: “педагогічна ситуація", “навчальна ситуація”, “виховна ситуація”, “педагогічна задача”, “педагогічне завдання”. Зокрема, серед дослідників варто назвати таких: О. Матвієнко, Л. Мільто, I. Осадченко, М. Поташник, І. Шакіров та ін.

Педагогічна ситуація - складова частина освітнього процесу, сукупність взаємопов'язаних факторів і явищ, які характеризують конкретний етап, період чи подію у школі чи дошкільному закладі та вимагають від педагогів оцінення, розпоряджень чи інших організаційних дій.

Найчастіше в сучасній педагогічні літературі виділяють два блоки педагогічних ситуацій: навчання і виховання.

Навчальний процес є складовою цілісного педагогічного процесу і реалізується через навчальні ситуації, які $\epsilon$ його елементарними структурними одиницями.

На думку М. Свтуха, “процес навчання як ціле охоплює, окрім входження учасників занять у навчальну ситуацію і виходу з неї, систему внутрішньо пов' язаних між собою ситуацій” [3]. Вважаємо, що навчальні ситуації на уроці як основній формі організації навчального процесу варто ототожнювати з етапами уроку і методами навчання. Тому виділяємо навчальні ситуації заплановані та незаплановані.

Другою важливою групою є ситуації, які відображають виховний процес - це виховні ситуації. У сучасній педагогічній науці використовується два терміни: “вихована ситуація" та “створення виховної ситуації. На думку О. Демченко, їх варто диференціювати, позаяк вони є близькими, але не синонімічними. Виховна ситуація, вважає дослідник, ще не $є$ методом виховання, а лише обставинами, які виникають у педагогічному процесі $[2,79]$.

Педагогічні задачі конкретизують педагогічну ситуацію. Їх традиційно розглядають інструментом творчості вчителя. Якщо при розв'язанні педагогічної ситуації педагог стоїть перед дилемою, який розв'язок йому вибрати (одна і та ж ситуація може вирішуватися різними способами), то при конкретній педагогічній задачі можлива конкретна відповідь. Ми вважаємо педагогічні ситуації є формами, методами організації освітнього процесу. Натомість задачі відображають прийоми

I. Осадченко зауважує, що центральним моментом розв'язання педагогічної ситуації $\epsilon$ формулювання педагогічної задачі [9].

У підготовці майбутніх педагогів до педагогічної взаємодії із дітьми дошкільного і молодшого шкільного віку зі внутрішньо переміщених сімей важливу роль відіграє процес розв'язування педагогічних ситуацій. 3 цією метою ми використовуємо технологію case-study.

Уважаємо, що процес аналізу та розв'язання педагогічних ситуацій $є$ варіативним у межах певного кластеру певного освітнього середовища.

Поняття “кластера" використовується у багатьох галузях знань. Кластер - це система, яка включає у себе основу (педагогічну ситуацію), шляхи та способи іiї розв'язання, а особливості використання у процесі практичної роботи (під час виробничої практики чи в ролі вчителя початкової школи або вихователя дошкільних закладів).

Характерними ознаками кластеру як системи виступає освітнє середовище: клас, дошкільна група, регіон, матеріальні ресурси (засоби навчання, оформлення навчально-виховного приміщення тощо); спільна діяльність (письмо, читання, розв'язування прикладів, опитування знань дітей, пояснення нового матеріалу, організація ігор і т.п.).

Кластерний підхід проявляється у групуванні навчально-професіних ситуацій та їх взаємоінтеграції. Це $є$ концепція розвитку освітнього процесу через створення (організацію) навчальнопрофесійних ситуацій, як розвивальних кластерів.

Кластер оформляється у формі грон, у центрі яких поставлена находиться педагогічна ситуація, від якої в різні боки відходять лінії, що відображають задачі та шляхи розв'язання. Важливо не тільки дати аналіз розв'язку, але й аргументувати, конкретизувати його.

Форми роботи з кластером різні: індивідуальні, групові, колективні.

Використання кластеру також сприяє творчому зростанню, допомагає студентам розглянути одну ситуацію з декількох точок зору, сприяє критичному мисленню.

Зауважимо, що підготовку студентів до педагогічної взаємодії із дітьми дошкільного і молодшого шкільного віку зі внутрішньо переміщених сімей здійснюємо через розв'язання виховних ситуацій, об'єднаних у кластер, який відображає шляхи соціокультурної адаптації дітей.

Кейс-метод - це технологія навчання, яка використовує реальні педагогічні ситуації. Метою 


\section{ПІДГОТОВКА СТУДЕНТІВ ДО ПЕДАГОГІЧНОЇ ВЗАЕМОДІЇ ІЗ ДІТЬМИ ДОШКІЛЬНОГО МОЛОДШОГО ШКІЛЬНОГО ВІКУ ЗІ ВНУТРІШНЬО ПЕРЕМШЩЕНИХ СІМЕЙ}

його застосування в освітньому процесі закладу вищої освіти $є$ навчання студентів, 3 використанням набутих теоретичних знань, розв'язувати практичні педагогічні ситуації, 3 якими вони можуть стикнутися в реальному житті. В основі кейс-методу лежить кейс. Залежно від функцій Ю. Сурмін виділяє різні типи кейсів:

Тренувальні, які допомагають формуванню навичок діяльності у змінних ситуаціях.

Навчальні, що сприяють оволодінню знаннями відносно динамічних стохастичних об’єктів.

Аналітичні забезпечують вироблення умінь $\mathrm{i}$ навичок аналітичної діяльності

Дослідницькі сприяють отриманню принципово нових знань відносно розвиваючих стохастичних об'єктів.

Систематизуючі впливають на систематизацію ситуаційного знання.

Прогностичні мають на меті отримання відомостей про майбутне стохастичної системи $[10,82]$.

Використання кейс-методу 3 метою підготовки майбутніх педагогів до педагогічної взаємодії із дітьми дошкільного і молодшого шкільного віку зі внутрішньо переміщених сімей використовуємо у процесі викладання педагогічних дисциплін і здійснюємо у два етапи.

На першому етапі, разом із студентами створюємо кластери кейсів, основний алгоритм яких включає: виховну ситуацію, чинники, що впливають на iï протікання, та завдання, які необхідно розв'язати.

Виховні ситуації, які лежать в основі кейсметоду, можуть:

- відображати як виховний процес, так і заходи, що сприяють його протіканню;

- бути спеціально створенними (цілеспрямовані) й спонтанними;

- мати ілюстративний, проблемний чи оцінний характер.

До основних чинників належить: характеристика особистості та педагогічної майстерності педагогічного працівника, особистості дитини, освітнього середовища й освітнього простору, де відбувається ситуація.

Завдання, які ставляться студентам 3 метою спрямування на розв'язання педагогічних ситуацій, мають бути конкретними і чіткими.

У процесі створення кейсів особливу роль відіграє теоретичне обгрунтування основних понять і положень.

Під час пандемії COVID 19, нами використовувався Padlet, який є мультимедійним ресурсом, універсальною онлайн-дошкою у формі стіни, полотна, сітки, трансляції, полиці для створення, спільного редагування та зберігання інформації. Це віртуальна стіна, на яку можна прикріплювати фото, файли, посилання на сторінки Інтернет, замітки.

При створенні кейсів також використовуємо сервіс для створення відеофрагментів 3 аудіо та текстовими коментарями EDpuzzle, який інтегрований з Google Classroom. За допомогою цього сервісу відеоролики із записами педагогічних ситуацій із популярних відеохостингів (YouTube чи Vimeo), та педагогічних ситуацій, що записані студентами під час виробничих практик, перетворюємо на кейси із завданнями.

Cервіс EDpuzzle використовуємо також на другому етапі реалізації технології кейс-методу. 3 цією метою студенти озвучують відео, записавши власні пояснення розв'язку педагогічної ситуації.

Другий етап реалізації технології кейс-методу присвячений процесу розв'язання педагогічних ситуацій.

Розв'язування педагогічних ситуацій здійснюємо за допомогою їх обговорення та програвання.

Як показує аналіз дослідження теорії та практики, програвання педагогічних ситуацій відбувається у напрямках, що відповідають самостійній підготовці фахівців, і буває репродуктивним, частково-пошуковим і творчим.

Репродуктивне програвання використовуємо на початкових етапах підготовки студентів до педагогічної взаємодії. Майбутнім педагогам пропонуються ситуації ілюстративного характеру. Перед ними ставлять завдання: проаналізувати варіанти протікання і розв'язку ситуації за допомогою визначеного алгоритму і програти. У таких випадках найчастіше використовуємо імітаційне моделювання, метою якого $є$ перетворити кожного студента на безпосереднього учасника освітнього процесу, який спрямований на пошук шляхів і способів розв'язання конкретних педагогічних проблем в умовах імітації того середовища, в якому йому доведеться працювати як майбутньому педагогу.

3 метою формування у студентів навичок аналізу педагогічних ситуацій і постановки завдань використовуємо частково-пошукове програвання педагогічних ситуацій, що зафіксовані на папері або у відео форматі, з використанням рольової гри.

Творче програвання педагогічних ситуацій включає конкретизацію задач і пошуку нових шляхів розв'язання ситуацій і здійснюється із використанням ділових ігор. 


\section{ПІДГОТОВКА СТУДЕНТІВ ДОПЕДАГОГІЧНОЇ ВЗАЄМОДІЇ ІЗ ДІТЬМИ ДОШКІЛЬНОГО І МОЛОДШОГО ШКІЛЬНОГО ВІКУ ЗІ ВНУТРІШНЬО ПЕРЕМШЩЕНИХ СІМЕЙ}

Зауважимо, що впровадження процесу розв'язування навчально-професійних ситуацій у підготовку майбутніх педагогів до педагогічної взаємодії із дітьми дошкільного і молодшого шкільного віку зі внутрішньо переміщених сімей $\epsilon$ результативним при використанні коучингового підходу до організації освітнього середовища в ЗВО.

Висновки та перспективи подальших досліджень. У сучасних умовах розбудови українського суспільства, внаслідок конфлікту на сході країни та окупації Криму є наявність “внутрішньо переміщених осіб”. Серед яких $є$ діти, у яких виникають проблеми адаптації до нових культурних та освітніх умов, здійснюється перебудова системи ціннісно-пізнавальних орієнтацій особистості, формуються нові типи міжособистісних стосунків. Вихователь у дошкільному закладі, вчитель початкових класів сприяють соціальній адаптації дітей, організовуючи педагогічну взаємодію в освітньому процесі. Тому виникає необхідність підготовки студентів до педагогічної взаємодії із дітьми дошкільного і молодшого шкільного віку зі внутрішньо переміщених сімей, яку варто здійснювати через розв'язання навчальнопрофесійних ситуацій.

Подальший науковий пошук слід спрямувати на конкретизацію алгоритмів розв'язування навчально-професійних ситуацій

\section{ЛІТЕРАТУРА}

1. Атрощенко Т., Зданевич Л. Аксіологічний підхід у формуванні полікультурної компетентності майбутніх вихователів закладів дошкільної освіти. Молодь і ринок, 2021. № 2/188. С. 6-11. https:// doi.org/10.24919/2308-4634.2021.230434.

2. Демченко О.П. Виховні ситуації в особистісно зорієнтованому просторі початкової школи. Київ: Видавничий Дім “Слово”, 2014. 416 с.

3. Євтух М. Б., Сердюк О. П. Соціальна педагогіка : підручник. Київ: МАУП, 2003. 232 с. URL: http://imanbooks.com/book 472 page 61

4. Закон України "Про забезпечення прав i свобод внутрішньо переміщених осіб". URL: https://zakon.rada.gov.ua/laws/show/1706-18\#Text.

5. Звіт Міністерства соціальної політики. URL: https://www.msp.gov.ua/news/19864.html

6. Киричук О.В. Проблеми психології педагогічної взаємодії. Психологія: респ. наук. зб. Київ: Освіта, 1991. Вип. 37. С. 3-12.

7. Кіліченко О.І. Розвиток діагностичних умінь учителів початкової школи у процесі розв'язування навчально-професійних ситуацій. Обрії : наук.пед.журн. Івано-Франківськ, 2016. № 1(42). С. 48-51.
8. Kilichenko O., Vovchok Y. Socio-cultural Adaptation of Children of Migrants in the Process of Ethnographic Tourism. Journal of History Culture and Art, 2019. 8(2). pp. 170-178. URL: http:// kutaksam.karabuk.edu.tr/index.php/ilk. doi:http:// dx.doi.org/10.7596/taksad.v8i2.2103

9. Осадченко I. I. Теорія і практика ситуаційного навчання у підготовці майбутніх учителів початкової школи : монографія. Умань : ПП Жовтий, 2011. 414 с.

10. Ситуационый анализ, или Анатомия Кейсметода/Под ред. Сурмина Ю.П. Київ: Центр инноваций и развития, 2002. 286 с

11. Чинники успішної адаптації дітей ВПО. URL: s78fbd8758b0cd0b7.jimcontent.com/.../ Чинники\%20адаптації\%20дітей\%20ВПО.pd

\section{REFERENCES}

1. Atroshhenko, T. \& Zdanevych, L., (2021). Aksiolohichnyi pidkhid u formuvanni polikulturnoi kompetentnosti maibutnikh vykhovateliv zakladiv doshkilnoi osvity [Anaxiological approach in the formation of multyculturalcompetence of future educators of preschool educationalestablishments]. Youth \& market. No. 2/188. pp. 6-11. https://doi.org/ 10.24919/2308-4634.2021.230434. [in Ukrainian].

2. Demchenko, O. P., (2014). Vykhovni sytuatsii v osobystisno zoriientovanomu prostori pochatkovoi shkoly [Educational situations in the personalityoriented space of primary school]. Kyiv, 416 p.[in Ukrainian].

3. Ievtukh, M. B. \& Serdiuk, O. P. (2003). Sotsialna pedahohika : pidruchnyk [Social pedagogy: a textbook]. Kyiv, 232 p. Available at: http:// imanbooks.com/book_472 page_61. [in Ukrainian].

4. Zakon Ukrainy "Pro zabezpechennia prav i svobod vnutrishno peremishchenykh osib" [Law of Ukraine "On Ensuring the Rights and Freedoms of Internally Displaced Persons"]. Available at: https:// zakon.rada.gov.ua/laws/show/1706-18\#Text[in Ukrainian].

5. Zvit Ministerstva sotsialnoi polityky [Report of the Ministry of Social Policy]. Available at: https:// www.msp.gov.ua/news/19864.html[in Ukrainian].

6. Kyrychuk, O.V. (1991). Problemy psykholohii pedahohichnoi vzaiemodii [Problems of psychology of pedagogical interaction]. Psychology. Kyiv, $112 \mathrm{p}$. [in Ukrainian].

7. Kilichenko, O.I. (2016). Rozvytok diahnostychnykh umin uchyteliv pochatkovoi shkoly u protsesi rozviazuvannia navchalno-profesiinykh sytuatsii [Development of diagnostic skills of primary school teachers in the process of solving the educational and professional situations]. Horizons: the scientificpedagogical journal. Ivano-Frankivsk. No. 1(42). pp. 48-51. [in Ukrainian]. 


\section{ДЕФОРМОВАНИЙ ТЕКСТ ЯК ЗАСІБ ПІДГОТОВКИ МАЙБУТНІХ УЧИТЕЛІВ ПОЧАТКОВОЇ ШКОЛИ ДО РОБОТИ В ДІАЛЕКТНОМУ СЕРЕДОВИЩІ}

8. Kilichenko, O. \& Vovchok, Y. (2019). Sociocultural Adaptation of Children of Migrants in the Process of Ethnographic Tourism. Journal of History Culture and Art. 8 (2). pp. 170-178. Available at: http://kutaksam.karabuk.edu.tr/ index.php/ilk. doi:http://dx.doi.org/10.7596/ taksad.v8i2.2103[in English].

9. Osadchenko I. I. (2011). Teoriia i praktyka sytuatsiinoho navchannia $\mathrm{u}$ pidhotovtsi maibutnikh uchyteliv pochatkovoi shkoly [Theory and practice of situational learning in the training of future primary school teachers]. Uman 414 p. [in Ukrainian].

10. Situatsionyy analiz, ili Anatomiya Keys-metoda (2002). [Situational Analysis, or Anatomy of the Case Method]. (Ed.). Surmyn, Ju.P. Kiev, 286 p. [in Russian].

11. Chynnyky uspishnoi adaptatsii ditei VPO [Factors of successful adaptation of children IDP] Available at: s78fbd8758b0cd0b7.jimcontent.com/... Чинники\%20адаптації\%20дітей\%20ВПО.pd.[in Ukrainian].

Стаття надійшла до редакції 25.03.2021

УДК 378.147:372.881

DOI:

Лариса Наконечна, кандидат філологічних наук, доцент, доцент кафедри педагогіки початкової освіти ДВНЗ “Прикарпатський національний університет імені Василя Стефаника”

\section{ДЕФОРМОВАНИЙ ТЕКСТ ЯК ЗАСІБ ПІДГОТОВКИ МАЙБУТНІХ УЧИТЕЛІВ ПОЧАТКОВОЇ ШКОЛИ ДО РОБОТИ В ДІАЛЕКТНОМУ СЕРЕДОВИЩІ}

Стаття присвячена актуальному питанню підготовки майбутніх учителів початкових класів до професійної діяльності в умовах діалектного мовного середовища. Автор розглядає один із засобів такої підготовки - текст і зокрема деформований текст, дає визначення поняття “деформований текст”, описує види деформованого тексту, аналізує мету ї використання та наводить приклади деформованих текстів, які можуть бути використані для підготовки учнів та студентів до роботи в діалектному середовищі.

Ключові слова: текст; деформований текст; професійна підготовка; майбутній вчитель початкової школи; заклад вищчої освіти.

תim. 6.

Larysa Nakonechna, Ph.D.(Philology), Associate Professor of the Primary Education Pedagogy Department Vasyl Stefanyk Precarpathian National University

\section{DEFORMED TEXT AS A MEANS OF PREPARING FUTURE PRIMARY SCHOOL TEACHERS TO WORK IN A DIALECT ENVIRONMENT}

The article is addressing the topical issue of future primary school teachers training, which is meant to help them get ready for the professional activity in dialectal language environment. The author considers one of the means of such preparation - the text and in particular, the deformed text.

An analysis of theoretical and didactic works of domestic experts shows that many issues remain unresolved, and many of them - within the context of the proposed study. The problem is considered urgent due to several factors. the lack of thorough scientific and methodological research and recommendations for the use of deformed text in the educational process; the need to clarify the essence of the deformed text and its varieties; the need to consider the deformed text as a means of forming the culture of speech of future primary school teachers, as well as a means of preparing students for teaching in a dialect environment.

The purpose of the article is to outline and actualize the problem of using deformed text in the system of future primary school teachers training meant to prepare them for their professional activity, in particular, within the dialect environment.

The author defines the concept of a deformed text, describes its types, analyzes its purpose and gives examples of deformed texts that can be used to prepare students to work in a dialect environment. The author also analyzes the current primary school curriculum and concludes that working with deformed text not only contributes to the formation of the students' language culture and prepares them for professional activities, but also improves the methodological knowledge of future primary school teachers.

Keywords: text; deformed text; professional training; future teacher, elementary school; higher education establishment.

П остановка проблеми. В умовах сучасного суспільства, яке все активніше ставить перед особистістю нові виклики і вимоги, сучасна мовна освіта в Україні - як дошкільна, шкільна, так і закладів вищої освіти, спрямовується на всебічне 